\title{
O PROJETO INTEGRADOR E A CENTRALIDADE DO TRABALHO PARA A FORMAÇÃO HUMANA NO PROGRAMA DE INTEGRAÇÃO DA EDUCAÇÃO PROFISSIONAL COM A EDUCAÇÃO BÁSICA NA MODALIDADE DE EDUCAÇÃO DE JOVENS E ADULTOS (PROEJA) IFES CAMPUS VITÓRIA/ES
}

\author{
E. T. ZEN ${ }^{1}$ e E. C. OLIVEIRA ${ }^{2}$ \\ ${ }^{1}$ Instituto Federal do Espírito Santo \\ ${ }^{2}$ Universidade Federal do Espírito Santo \\ elieserzen@hotmail.com¹; ednaoliveira@yahoo.com.br ${ }^{2}$
}

Artigo submetido em fevereiro/2014 e aceito em março/2014

\section{RESUMO}

A pesquisa busca refletir sobre a centralidade do trabalho como principio educativo na formação humana na Educação Profissional integrada à Educação de Jovens e Adultos (EJA) no Ifes campus de Vitória/ES. A investigação envolve o desenvolvimento e avaliação do Projeto Integrador com alunos do Proeja. A pesquisa de natureza qualitativa utiliza-se da metodologia da pesquisa-ação que tem como características a intervenção e a transformação de uma determinada realidade. A abordagem teórica se fundamenta na compreensão do trabalho como dimensão ontológica na formação humana dos educandos do Proeja. Os resultados indicam que o Projeto Integrador contribuiu para a integração entre formação profissional e formação geral; para a autonomia intelectual e ética dos alunos e para o resgate da centralidade do trabalho no currículo do Proeja.

PALAVRAS-CHAVE: Trabalho, Formação Humana, Projeto Integrador, Proeja.

\section{DESIGN AND INTEGRATOR CENTRALITY WORK FOR HUMAN FORMATION IN THE INTEGRATION OF PROFESSIONAL EDUCATION PROGRAM WITH A BASIC EDUCATION IN THE MODE OF YOUTH AND ADULT EDUCATION (PROEJA) IFES CAMPUS VITÓRIA/ES}

\begin{abstract}
The research seeks to reflect on the centrality of work as an educational principle in human development in the Integrated Professional Education Youth and Adult Education (EJA) at IFES campus Vitória/ES. The research involves the development and evaluation of the Project Integrator with students PROEJA. The qualitative research is used the methodology of action research which has the characteristics intervention and
\end{abstract}

transformation of a given reality. The theoretical approach is based on understanding the work as an ontological dimension in human PROEJA the students' education. The results indicate that the Integrator Project contributed to the integration between vocational training and general education, for intellectual autonomy and ethics of the students and to the rescue of the centrality of work in curriculum PROEJA.

KEYWORDS: Work, Human Formation, Project Integrator, PROEJA 


\section{INTRODUÇÃO}

Refletir sobre a centralidade do trabalho na formação de jovens e adultos do Proeja faz-se necessário em um duplo sentido, como parte da disputa de outro modelo de sociedade, que supere a sociedade capitalista e como compromisso histórico na formação e emancipação do gênero humano.

O atual contexto do capitalismo tem originado uma grande produção de exclusões de todos os tipos: do trabalho, da educação, da saúde, da moradia e podemos afirmar que no contexto histórico-social do capitalismo a individualidade humana se encontra alienada da natureza (danificada pela ganância dos donos do mundo que controlam o sistema metabólico do capital), dos demais seres humanos e de si mesmo, ou seja, o trabalho perde sua dimensão ontologicamente formadora do ser humano e se converte em meio de alienação do trabalhador, de tal forma que o mesmo não se reconheça nos objetos e no mundo que ele mesmo criou.

De acordo com os dados do IBGE/2010, o número de pessoas em condições de extrema pobreza (com renda domiciliar per capita inferior a um quarto de salário mínimo) é hoje de 21,7 milhões em todo o Brasil. A taxa de desemprego é de $8,4 \%$ da população economicamente ativa e o grau de informalidade é de $55,1 \%$ do total de trabalhadores ocupados, em 2006 . Segundo Coelho (2008) as desigualdades educacionais constituem, ao lado da pobreza, uma das formas de exclusão social no Brasil. O ensino fundamental (nove anos de escolaridade), etapa caracterizada pelo direito, garantido a todos pela Constituição Federal, ainda não foi alcançado por cerca de 65,9 milhões de brasileiros de 15 anos ou mais. Apenas 26,8 milhões haviam concluído a educação básica (11 anos ou mais de estudo), cerca de $19,6 \%$ do total da população do país. Da população economicamente ativa, 10 milhões de brasileiros maiores de 14 anos e integrados à atividade produtiva são identificados como analfabetos ou subescolarizados.

Em nossa sociedade, em que mais de 65 milhões de jovens e adultos, ou seja, mais de um terço da população interrompeu ou não teve acesso à educação básica completa, como demonstra - Documento Base do Programa de Integração da Educação Profissional à Educação Básica na Modalidade de Educação de Jovens e Adultos (BRASIL, 2007), o número de sujeitos de 15 anos ou mais sem conclusão do Ensino Fundamental é ainda de 65,9 milhões de brasileiros, a oferta de educação para jovens e adultos, prevista na Lei de Diretrizes e Bases da Educação (LDB) de 1996 torna-se imprescindível como condição de transformação e construção de uma sociedade justa e autônoma.

Nesse sentido, cabe perguntar qual o lugar que o trabalho ocupa no percurso formativo dos alunos do Proeja. Compreendemos que o trabalho em sua dupla dimensão histórica e ontológica é uma categoria central na formação humana dos jovens e adultos trabalhadores. O processo educativo não deve se converter em um cão de guarda do capital (MÉSZÁROS, 2005), mas possibilitar ao trabalhador o desenvolvimento das dimensões política, reflexiva, crítica, ativa, a fim de transformar a si mesmo e o mundo.

Do ponto de vista histórico ao analisarmos as políticas de formação para o trabalhador brasileiro podemos perceber que essas dimensões tiveram pouco ou nenhum avanço na perspectiva da emancipação humana. A ideologia capitalista, de que a educação para as classes populares é inferior, perpassa todas as tentativas da escolarização e preparação dos trabalhadores 
em nosso país. Para os pobres uma educação mínima, sem criticidade, com apenas os rudimentos da cultura da leitura, escrita e da matemática. Para reforçar essa visão da precária formação destinada às classes trabalhadoras, Kuenzer (1998, p. 33) faz a seguinte análise:

[...] a formação de trabalhadores e cidadãos no Brasil constituiu-se historicamente a partir da categoria dualidade estrutural, uma vez que havia uma nítida demarcação da trajetória educacional dos que iriam desempenhar as funções intelectuais ou instrumentais, em uma sociedade cujo desenvolvimento das forças produtivas delimitava claramente a divisão entre capital e trabalho [...] ruptura entre as atividades de planejamento e supervisão por um lado e de execução por outro.

Refletindo sobre a dualidade estrutural da educação brasileira de uma educação pobre para os pobres, Neves (2000), afirma que a reestruturação do capitalismo e a nova forma de organização e gestão do trabalho, decorrentes das mudanças no mundo do trabalho, defendida pelos organismos internacionais (Banco Mundial, FMI, OIT) acarretaram:

[...] políticas educativas de cunho conservador, particularmente nos países periféricos ao núcleo orgânico do capital [caso do Brasil]. As reformas educativas impostas à sociedade brasileira na década 1990 refletem esse contexto e a postura subserviente e associada da classe dominante (NEVES, 2000, p. 22).

Questiona-se aqui a dualidade estrutural da educação brasileira e procura abordar as categorias "trabalho, educação e emancipação" numa perspectiva de superação da lógica da pedagogia do capital. Assim este texto tem como escopo refletir sobre o processo formativo de jovens e adultos trabalhadores do Ifes de Vitória-ES, problematizando a categoria trabalho e sua importância no processo formativo dos jovens e adultos trabalhadores do Proeja na perspectiva da emancipação humana.

Podemos afirmar que o trabalho como uma atividade humana fundamental, ao ser introduzido no processo educativo e no currículo, permite ao educando do Proeja compreender, como se dá o movimento de construção da realidade social e ao mesmo tempo refletir sobre sua atuação como cidadão no sentido de participar como sujeito crítico na transformação da sociedade. Segundo Ramos (2003), do ponto de vista do capital, a dimensão ontológica do trabalho é subsumida à dimensão produtiva, pois nas relações capitalistas, o sujeito é o capital e o homem é o objeto. Nesse sentido, para assumir o trabalho como princípio educativo é preciso considerar e superar a lógica do capital:

Chegamos ao fim do século XX com a seguinte contradição: a ciência e a técnica, que têm a virtualidade de produzir uma melhor qualidade de vida, ocupar os seres humanos por menos tempo nas tarefas de produzir para a sobrevivência e liberálos para o tempo livre - tempo de escolha, de fruição, de lazer, sob as relações do capitalismo tardio produzem o desemprego estrutural ou o trabalho precarizado (FRIGOTTO, 2005, p. 70).

É neste ponto que reside o sentido de integração entre o mundo do trabalho e a educação: a constatação da identidade entre as capacidades demandadas pelo exercício da cidadania e pela atividade produtiva, o que permitiria construir um currículo do Proeja em que se pudesse superar a dicotomia entre a racionalidade técnica e o caráter abstrato dos ideais de formação humana. 


\section{O PROJETO INTEGRADOR E A CENTRALIDADE DO TRABALHO COMO PRINCÍPIO EDUCATIVO NO PERCURSO FORMATIVO DO EDUCANDO DO PROEJA NO IFES CAMPUS VITÓRIA/ES}

A proposta da rede federal de oferecer educação e formação profissional de qualidade tem sido realizada de uma maneira muito parcial, atingindo um estrato muito pequeno da população brasileira. $\mathrm{O}$ alto grau de seletividade que caracteriza a entrada na instituição, além de outros fatores, contribui para configurar um ensino altamente elitizado, voltado para atender os anseios dos grupos socialmente privilegiados. Esse foco pouco tem contribuído para um avanço na discussão entre os profissionais da rede sobre as finalidades do ensino médio e da formação profissional, prevalecendo um ensino de cunho propedêutico e voltado principalmente para o mercado de trabalho.

A entrada da modalidade EJA na rede tem provocado conflitos na medida em que suscita embates teórico-práticos em torno dessa proposta de educação exatamente porque traz no seu bojo o questionamento do sentido atribuído à escolarização e à formação profissional. Enquanto modalidade que se propõe a reparar, equalizar e qualificar (PARECER CNE/CEB 11/2000) a educação de jovens e adultos tem como meta o resgate do sujeito na perspectiva da cidadania (PAIVA, 2009). A partir desse questionamento é possível conceber a EJA na perspectiva de uma cidadania popular, requerendo, então, pensá-la em outra base antropológica, aquela que afirma a dignidade dos sujeitos historicamente excluídos do direito à educação e à totalidade dos bens necessários à vida. Dessa forma, busca-se superar a ideologia neoliberal burguesa que tem transformado a educação em mercadoria e o direito à educação em benefício. Referimo-nos a proposta do Proeja de promover uma:

[...] formação humana, no sentido lato, com acesso ao universo de saberes e conhecimentos científicos e tecnológicos produzidos historicamente pela humanidade, integrada a uma formação profissional que permita compreender o mundo, compreender-se no mundo e nele atuar na busca de melhoria das próprias condições de vida e da construção de uma sociedade socialmente justa. A perspectiva precisa ser, portanto, de formação na vida e para a vida e não apenas de qualificação do mercado ou para ele. (BRASIL, 2007, p. 07).

A burguesia brasileira sempre negou a escolaridade básica e, como conseqüência, a formação profissional efetiva à maioria dos jovens e adultos trabalhadores. Em seu projeto sempre esteve uma educação unidimensional a serviço do mercado e do capital. Seu objetivo sempre consistiu na oferta de uma educação profissional descolada de uma formação de cultura geral estruturante da consciência ativa dos homens.

O surgimento do Proeja no âmbito da rede federal por meio do decreto 5478/2005 e posteriormente a extensão do Programa para além da rede federal, pelo decreto 5840/2006, vem possibilitar a participação de um novo perfil de aluno, oriundo da escola pública, porém com diferentes níveis de cognição, faixa etária e expectativas de vida. A partir da análise do que se apresentava nesse perfil, entendeu-se que novas práticas pedagógicas seriam necessárias para atender a essa demanda. Buscou-se então, propostas de educação que considerassem, preferencialmente, as vivências, experiências e os saberes dos próprios alunos. Nesse sentido, Moura e Pinheiro (2009, p.100) afirmam: 
Os sujeitos da EJA trazem consigo um conjunto de características próprias, como descontinuidades de estudos, reprovações, lacunas cognitivas, necessidade de trabalhar para ajudar na renda familiar ou para manter a própria família, entre outras amplamente conhecidas na literatura específica da EJA, que os diferencia fortemente dos demais.

Visando integrar os vários conhecimentos a partir da construção de um projeto único e comum da turma, a coordenação do Proeja propôs a inserção na grade curricular dos cursos de um componente que, contemplasse por meio do desenvolvimento de um tema gerador, a interdisciplinaridade entre as diferentes disciplinas, o que se deu por meio do projeto integrador ${ }^{1}$. Nesse sentido, o projeto integrador busca contribuir para superar a dualidade estrutural que perpassa a educação em nosso país, favorecendo a formação integral do aluno do Proeja.

\section{O PROJETO INTEGRADOR NA EDUCAÇÃO PROFISSIONAL INTEGRADA À EDUCAÇÃO DE JOVENS E ADULTOS: DESAFIOS E POTENCIALIDADES NA FORMAÇÃO HUMANA DO EDUCANDO DO PROEJA IFES CAMPUS VITÓRIA-ES.}

O método de pesquisa utilizado no desenvolvimento da investigação é de natureza qualitativa pela sua importância no estudo sobre as concepções dos sujeitos envolvidos no cotidiano escolar, com opção pela metodologia da pesquisa-ação. Segundo (THIOLLENT, 1996) a pesquisa-ação é um tipo de pesquisa social com base empírica, concebida e realizada junto com uma ação ou resolução de um problema coletivo onde os pesquisadores e participantes da situação estão envolvidos de forma participativa e colaborativa, com objetivo de contribuir para a resolução do problema central da pesquisa, aumentar o conhecimento sobre determinadas situações e possibilitar ao grupo em estudo a tomada de consciência. Os instrumentos de pesquisa utilizados no desenvolvimento da investigação foram: acompanhamento das aulas da disciplina projeto integrador em seus diferentes momentos ou fases de elaboração (teoria, prática e práxis); registro pelo professor orientador das etapas de construção do projeto integrador; análise das apresentações finais dos projetos realizadas pelos alunos.

O componente curricular projeto integrador está organizado em três etapas: metodologia 1, metodologia 2 e metodologia 3. Em metodologia 1, trabalha- se com os alunos a importância da leitura, tipos de leituras, como fazer um fichamento, resumos de um texto, até uma breve introdução às etapas de um projeto de pesquisa (tema, objetivos, justificativa, metodologia, problema, cronograma, referencial teórico) e a escolha, delimitação e elaboração de uma pesquisa teórica sobre um tema de interesse coletivo da turma; na segunda etapa do desenvolvimento do projeto integrador a disciplina de "metodologia 2" tem como tarefa a discussão em torno da relação entre a teoria e a prática a partir do tema que foi escolhido; a terceira fase tem como meta a aplicação do projeto a uma determinada realidade (escola, sindicatos, prefeituras etc.).

\footnotetext{
${ }^{1} \mathrm{O}$ projeto integrador se constituiu em um componente curricular diferente dos demais por não apresentar em sua estrutura um conteúdo prescrito ou a priori como as demais disciplinas. Os conteúdos a serem desenvolvidos pelos alunos surgem a partir das vivências, experiências e saberes dos alunos e professores, ou seja, da prática social na qual estão inseridos, seja ela entendida como o mundo do trabalho, o universo familiar, religioso, cultural e escolar. É a partir da problematização e reflexão dessa realidade que professores e alunos escolhem um tema gerador para desenvolverem durante os três módulos do curso, constituindo uma unidade entre teoria e prática.
} 
Dentro dos limites desse texto relatamos apenas o desenvolvimento da primeira etapa do projeto. Ao iniciar o trabalho de orientação às turmas buscamos estabelecer um diálogo sobre suas experiências, saberes, valores e o porquê escolheram o curso do Proeja. Partindo das informações que os alunos traziam procedemos a uma breve explanação do que é o Programa, a modalidade (EJA) e o curso que estavam ingressando. Passamos a perceber daí que os alunos tomavam conhecimento do Programa e da própria modalidade (EJA) se identificavam mais com a área profissional escolhida e se sentiam motivados a continuar sua trajetória escolar.

Nesse movimento de problematização da modalidade (EJA), do Programa e dos cursos do Proeja (Metalurgia, Edificações ou Segurança do Trabalho) foram surgindo questões que interessavam diretamente ao desenvolvimento do projeto integrador. O tema do projeto integrador ao ser escolhido coletivamente pela turma tinha por base três dimensões (política, ética e técnica) de todo fazer humano, o que incluía em nossas reflexões o questionamento das próprias relações sociais de produção das desigualdades sociais geradas pelo sistema capital.

A turma analisada era composta de 17 alunos, de idade entre 20 a 45 alunos, sendo a maioria mulheres. No início do desenvolvimento do projeto integrador, no segundo módulo do curso (2012/1), depois de quase dois meses conversando e dialogando sobre questões mais estruturais do capitalismo, um dos alunos sugeriu como tema para o projeto integrador: "desenvolvimento sustentável na construção civil". Ao refletirmos sobre as grandes questões de nosso tempo (trabalho, cultura, ecologia) os alunos chegaram à conclusão que a destruição da natureza pelo homem era um tema fundamental e que tinha relação direta com as atividades do curso escolhido por eles (edificações).

A partir da escolha da temática tem início a atividade de pesquisa das etapas do projeto integrador. Após uma breve explanação para a turma de cada etapa do projeto (tema, objetivos, problema, justificativa, metodologia, cronograma, campo teórico) organizamos a turma em duplas para dar início à fase de elaboração escrita do projeto. Nesse primeiro momento de elaboração do projeto há certa "confusão" de uma etapa com outra. Por exemplo, era comum confundir os objetivos com a justificativa, gerando dificuldades na escrita, mas à medida que o debate coletivo avança e que os alunos participam das discussões as dúvidas vão sendo esclarecidas. Para a etapa de elaboração teórica do projeto organizamos a turma em grupos e ou duplas, disponibilizamos o laboratório de informática e a biblioteca para que os alunos pudessem ter acesso à internet no desenvolvimento do trabalho. Durante as aulas a turma teve acesso aos laboratórios de informática para a construção das etapas do projeto. Esse momento é realizado sob a orientação do professor que procurava sugerir sites de busca de textos, documentários, jornais, revistas, livros e outros meios que possibilite aos alunos um conhecimento, mesmo que inicial, mas necessário com a temática escolhida. Ao encontrarem algum material, como texto, documentário, vídeo, artigo de revista ou jornal sobre a temática, os alunos salvam em meio eletrônico ou no próprio computador, para posteriormente disponibilizar no e-mail da turma e ser objeto de estudo em sala.

Uma das dificuldades vivenciadas pelos alunos nessa fase consistiu no estado em que se encontravam alguns laboratórios de informática, que muitas vezes, funcionavam de forma muito precária ou não funcionavam, dificultando o acesso à internet e à pesquisa. Outro espaço importante para o desenvolvimento da pesquisa é a biblioteca. Após esse momento inicial no laboratório de informática os alunos vão à biblioteca da escola para aprofundarem a leitura no tema escolhido. Ao encontrar algum artigo, texto, revista ou livro que abordem o tema da turma 
os alunos são orientados a fazer um resumo ou no caso de um texto muito extenso ou um livro, pediam emprestado na biblioteca para ter um tempo maior de estudar o material.

Depois desses dois momentos os alunos voltavam para a sala de aula para dar continuidade ao trabalho de elaboração das etapas do projeto, agora de posse do material em mãos. O professor então solicita aos alunos, que realizem uma leitura atenta do material, procurando identificar as ideias principais e as palavras chaves, para posteriormente fazer um fichamento do material. Após essa primeira leitura buscando identificar as concepções fundamentais do texto e as palavras fundamentais, o professor solicitava aos alunos que reescrevessem o texto com suas palavras, o que passaria a integrar o corpo teórico do trabalho.

Entre os desafios para a leitura e a escrita de um projeto, está a negação do direito ao conhecimento às classes populares. $O$ fato de alguns alunos estarem afastados da escola por muito tempo, somando-se com as precárias condições da educação básica ofertada tanto pelas prefeituras quanto pelo Estado, em que o aluno muitas vezes conclui o Ensino Fundamental e Médio sem a necessária qualificação exigida pelo grau de escolaridade que alcançou é apontado por muitos alunos como um dos fatores que os levaram a cursar o Proeja. Isto tem provocado um processo histórico de negação do direito ao conhecimento da leitura e escrita na formação dos jovens e adultos, especialmente os filhos das classes trabalhadoras.

Nesse momento, conversamos sobre o significado da leitura como apreensão da mensagem global de um texto ou de um livro pelo leitor. Então em seguida dialogamos com os alunos sobre as etapas da atividade de leitura de um texto, para fins de conhecimento e compreensão de seu conteúdo, entre elas procuramos destacar: etapa da análise textual; etapa da análise temática; etapa da análise interpretativa; etapa de problematização e finalmente a etapa da reelaboração reflexiva.

Vencido o desafio da escrita do projeto na disciplina, os alunos se preparam então para a apresentação do final do projeto. Para realizar a apresentação do trabalho os alunos preparam um conjunto de slides sobre as etapas do projeto e contam com a ajuda e compreensão de outros professores, que auxiliam na correção do português, na formatação dos slides e em outros detalhes importantes. A apresentação do projeto geralmente ocorre no final do semestre letivo de cada módulo dos cursos do Proeja e está prevista no calendário escolar.

A apresentação dos projetos é um momento privilegiado para toda a comunidade escolar envolvida diretamente com o Proeja, pois é um momento coletivo, em que se discutem a partir de uma temática escolhida e apresentada pelos próprios alunos, questões que dizem respeito diretamente à modalidade (EJA), ao Programa e em específico ao curso e área de atuação profissional. É um momento coletivo em que professores e alunos mediados pelo projeto integrador refletem sobre questões de natureza política, econômica, cultural, social, ética e ambiental, recriando o conhecimento para além da fragmentação das disciplinas escolares, tendo como premissa a concepção de conhecimento como totalidade social, favorecendo dessa forma, a formação integral do aluno do Proeja, na medida em que articula e integra no desenvolvimento do projeto, em todas as suas fases, a formação geral e a formação técnica. 


\section{CONSIDERAÇÕES FINAIS}

Como resultados da investigação pode-se afirmar que o projeto integrador contribui para a integração entre a educação profissional técnica e a educação geral nas seguintes dimensões:

- Fortalecimento do Proeja como política pública;

- Visibilidade e conhecimento da instituição por parte da comunidade extraescolar, por meio da apresentação dos projetos integradores em escolas estaduais, municipais e particulares; sindicatos; associações; prefeituras; empresas, entre outros;

- O desenvolvimento da consciência crítica e cidadã do aluno do Proeja;

- Contribui para a formação da autonomia intelectual, ética, política e humana dos alunos;

- Proporciona uma ação interventora na realidade sócio-laboral por meio do resgate da centralidade da categoria trabalho;

- Contribui para aprofundar o diálogo necessário entre as disciplinas das áreas de formação profissional (metalurgia, edificações e segurança do trabalho) e formação geral;

- Em síntese, o projeto integrador tem contribuído juntamente com as demais disciplinas que compõe o currículo para um processo formativo de cidadãos-profissionais capazes de compreender a realidade social, econômica, política, cultural e do mundo do trabalho, para nela inserir-se e atuar de forma ética e competente, técnica e politicamente, visando à transformação da sociedade em função dos interesses sociais e coletivos especialmente os da classe trabalhadora.

\section{REFERÊNCIAS BIBLIOGRÁFICAS}

1. BRASIL. Decreto n. 5.840, de 13 de julho de 2006. Institui, no âmbito federal, o Programa Nacional de Integração Profissional com a Educação Básica na Modalidade de Educação de Jovens e Adultos - PROEJA, e dá outras providências. Brasília, DF, 2006 a.

2. BRASIL, Ministério da Educação. PROEJA - Documento Base. MEC, SETEC: Brasília, 2007.

3. CONSELHO NACIONAL DE EDUCAÇÃO. CÂMARA DE EDUCAÇÃO BÁSICA (Brasil). Parecer no 11, de 05 de maio de 2000. Institui as Diretrizes Curriculares Nacionais para a Educação de Jovens e Adultos. Brasília, DF, 2000.

4. COELHO, Maria Inês de Matos. Identidades e formação nos percursos de vida de jovens e adultos trabalhadores: desafios ao Proeja. In: Revista Brasileira da Educação Profissional e Tecnológica. Ministério da Educação, Secretaria de Educação Profissional e Tecnológica. V.1, n.1, jun. 2008. Brasília: MEC, SETEC, 2008.

5. FRIGOTTO, Gaudêncio. Concepções e mudanças no mundo do trabalho e o ensino médio. In: FRIGOTTO, Gaudêncio; CIAVATTA, Maria e RAMOS, Marise Nogueira (Orgs). Ensino Médio integrado: concepção e contradições. São Paulo: Cortez, 2005.

6. MÉSZÁROS, István. A educação para além do capital. São Paulo, Boitempo, 2005. 
7. NEVES, Lúcia Maria Wanderley. Brasil 2000: nova divisão de trabalho na educação. 2a ed. São Paulo: Xamã, 2000.

8. KUENZER, Acacia Z.. As mudanças no mundo do trabalho e a educação: novos desafios para a gestão. In: FERREIRA, Naura S. C. Gestão democrática da Educação: atuais tendências, novos desafios. São Paulo, Cortez. 1998.

9. RAMOS, Marise Nogueira. O "novo" Ensino Médio à luz de antigos princípios: trabalho, ciência e cultura. Boletim Técnico do SENAC. Rio de Janeiro, v.29, n.2, maio/ago, 2003.

10. PAIVA, Jane. Os sentidos do direto à educação de jovens e adultos. Petrópolis: DP et Alii; Rio de Janeiro: FAPERJ, 2009.

11. THIOLLENT, Michel. Metodologia da Pesquisa-ação. São Paulo: Ed. Cortez, 1996. 